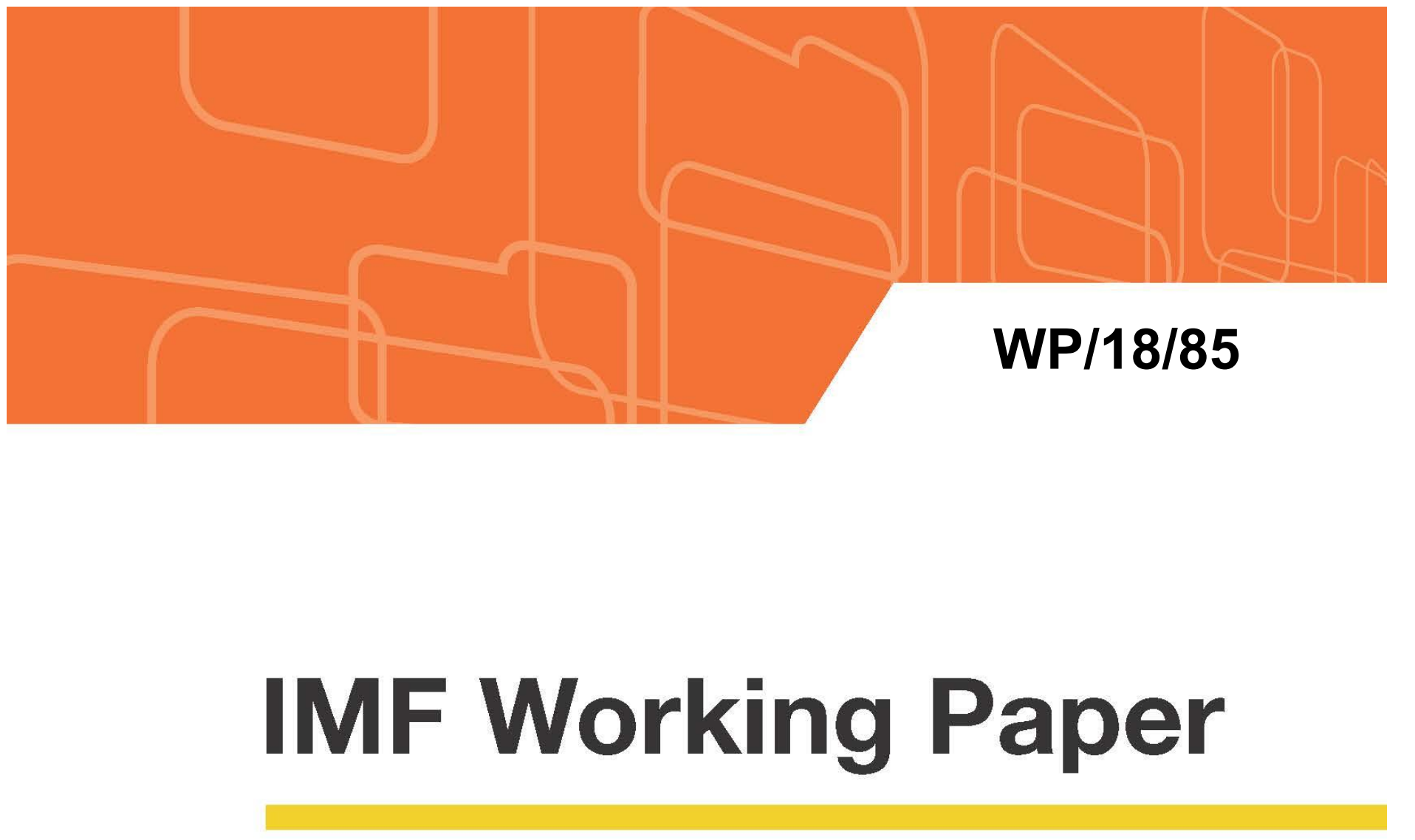

\title{
Decoupling of Emissions and GDP: Evidence from Aggregate and Provincial Chinese Data
}

by Gail Cohen, Joao Tovar Jalles, Prakash Loungani,

Ricardo Marto and Gewei Wang 


\title{
IMF Working Paper
}

\author{
Research Department
}

\section{Decoupling of Emissions and GDP:}

\section{Evidence from Aggregate and Provincial Chinese Data}

\author{
Gail Cohen, Joao Jalles, Prakash Loungani, Ricardo Marto and Gewei Wang* \\ Authorized for distribution by Chris Papageorgiou
}

April 2018

\begin{abstract}
IMF Working Papers describe research in progress by the author(s) and are published to elicit comments and to encourage debate. The views expressed in IMF Working Papers are those of the author(s) and do not necessarily represent the views of the IMF, its Executive Board, or IMF management.
\end{abstract}

\begin{abstract}
We provide a comprehensive analysis of the relationship between greenhouse gas (GHG) emissions and GDP in China using both aggregate and provincial data. The Kuznets elasticity is about 0.6 for China, higher than that in advanced countries but below that of major emerging markets. The elasticity is somewhat lower for consumption-based emissions than for productionbased emissions, providing mild evidence consistent with the "pollution haven" hypothesis. The Kuznets elasticity is much lower for the last three decades than for the three previous decades, suggesting a longer-term trend toward decoupling as China has become richer. Further evidence of this comes from provincial data: richer provinces tend to have smaller Kuznets elasticities than poorer ones. In addition to the trend relationship, we find that the Environmental Okun's Law holds in China.
\end{abstract}

JEL Classification Numbers: E32, O44, Q43, Q54, Q56

Keywords: Emissions, Environmental Okun's Law, Kuznets Curve, China, Provinces

Author's E-Mail Address: gcohen@nas.edu,jjalles@imf.org, ploungani@imf.org, rmarto@imf.org, gewei.wang@ nottingham.edu.cn

*We thank seminar participants at the 2017 International Conference on Energy Finance in Hangzhou for their useful suggestions. We also thank Philippe Wingender for useful comments. All errors are our own. The views expressed in this paper are those of the authors and do not necessarily represent those of their affiliation. 


\section{Contents}

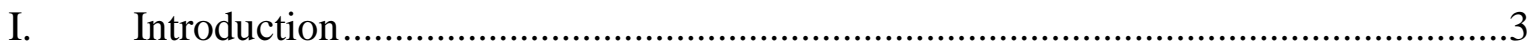

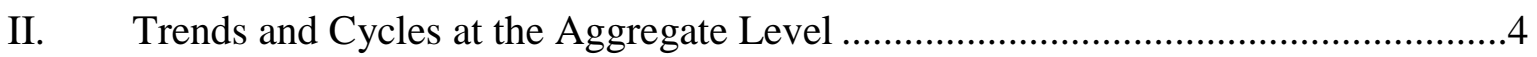

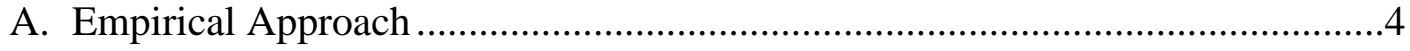

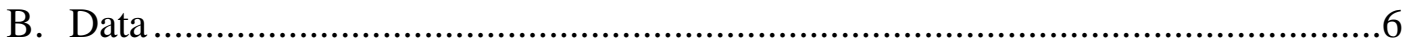

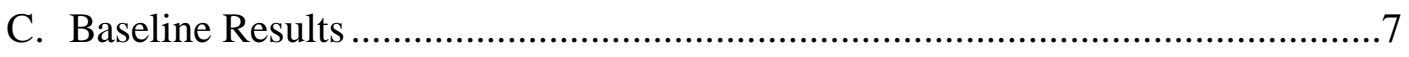

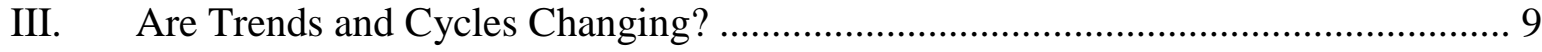

A. A Longer Time Horizon Perspective .............................................................10

B. A Provincial Level Perspective .........................................................................11

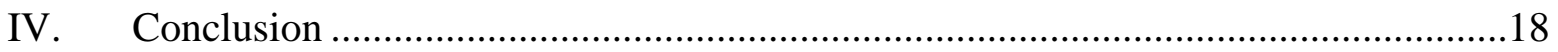

\section{List of Figures}

1. Consumption- and Production-Based GHG Emissions ..................................................

2. Trends and Cycles across Different Filtering Methods .................................................8

3. Trends and Cycles in Production- and Consumption-Based Emissions ...........................

4. Trends and Cycles in the Eastern Region ………......................................................12

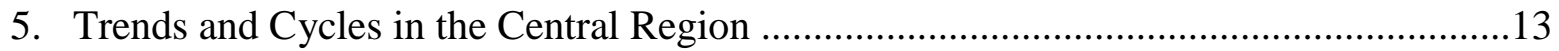

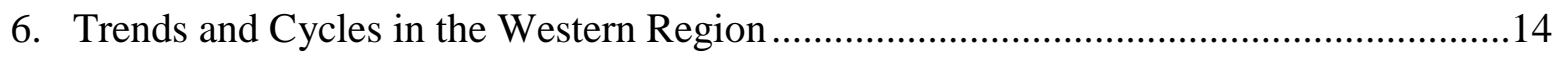

7. Kuznets Elasticities and Real GDP Per Capita across Chinese Provinces ......................17

8. China's Provinces and U.S. States mean Kuznets Elasticities by Inter-Quintiles Ranges

A1. Kuznets Residuals at the Aggregate Level .............................................................

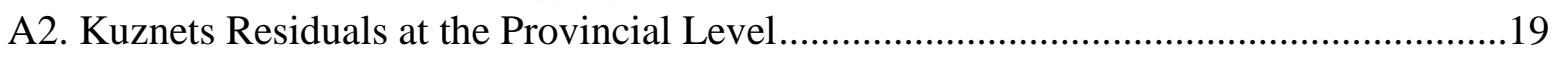

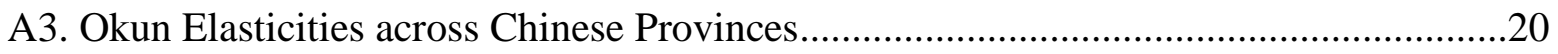

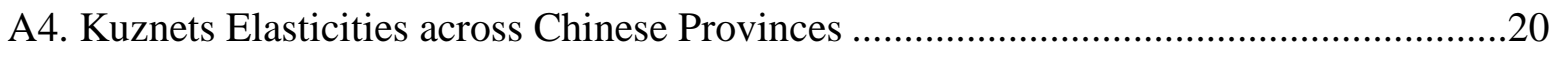

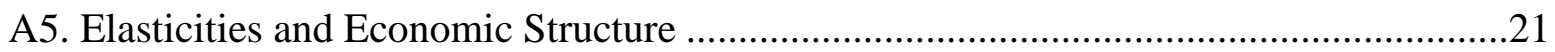

\section{List of Tables}

1. Contrasting Elasticities at the Aggregate Level...........................................................

2. Long-Run Elasticities at the Aggregate Level .............................................................11

3. Okun and Kuznets Elasticities at the Provincial Level .................................................16

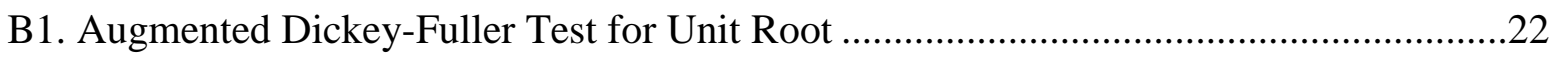

B2. Okun and Kuznets Correlations at the Provincial Level ................................................22

Appendix

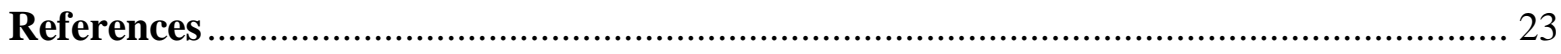




\section{INTRODUCTION}

China is the world's largest greenhouse gas (GHG) emitter. It contributes 23 percent of world emissions, which is larger than its 19 percent share of the world's population and 15 percent share of the world's GDP. Progress on global climate change goals will be difficult to achieve unless the pace of emissions slows down significantly in China. Some argue that China's high emissions are due in large part to its major role in the international trading system since its accession to the WTO; the "pollution haven" hypothesis asserts that "emissions reductions observed in developed nations are partly the result of shifting dirty production to developing nations" such as China (Kearsley and Riddel (2010); see also (Ederington et al. (2005), He (2006) and Dean et al. (2009)).

In this paper, we provide evidence on the relationship between emissions and GDP growth in China and investigate whether there are signs of decoupling between the two. As in Cohen et al (2017), we distinguish the trend relationship between emissions and GDP from the cyclical relationship. The Kuznets elasticity - the response of trend emissions to trend GDP - is about 0.6, which is higher than that in major advanced economies but lower than in many emerging markets. The estimate is robust to alternate methods of detrending the data such as the commonly-used Hodrick-Prescott filter and the new filter proposed by Hamilton (2017). We find that the elasticity is somewhat higher with production-based emissions than with consumption-based emissions. The direction of these results is consistent with the pollution haven hypothesis but the quantitative difference between the two elasticities is not large, and suggests that shifts in the allocation of global production across countries are not a major driver of shifts in the pattern of emissions growth.

We find encouraging signs that the Kuznets elasticity may be declining, both from an analysis of longterm aggregate data and from provincial data. In aggregate data, the Kuznets elasticity was almost three times as large over the 1950 to 1982 period than in the period since then. This suggests that while the opening up of the economy to reforms in the 1980s - and the subsequent strong economic growthhave contributed to growth in emissions, the likely scenario in the absence of reforms would have been even higher emissions growth. Our analysis for 29 provinces reveals that the Kuznets elasticity initially increases with provincial per capita real GDP but then declines; the inverted U-shape relationship between the intensity of emissions-GDP relationship and the level of per capita GDP is reminiscent of the Environmental Kuznets Curve (Grossman and Krueger $(1991,1995)$ ). As with the evidence on the decline in the aggregate Kuznets elasticity over time, the results from provincial data hold out the hope that the relationship between emissions and GDP growth will weaken as China gets richer.

We also provide evidence on the cyclical relationship between emissions and GDP growth, viz., on the Environmental Okun's Law (EOL). The Okun elasticity - the response of the cyclical component of emissions to the cyclical component of GDP_ranges from 0.35 to 0.65 , depending on the filtering method used and on whether production-based or consumption-based emissions are used. We find evidence of asymmetry in EOL: the Okun elasticity is higher for booms than during busts, and thus China's emissions go up more when GDP is above trend than they decrease when GDP is below trend. To our knowledge, this is the first study to provide a comprehensive look at the extent of decoupling of emissions and output for China, looking at both trends and cycles, using both production-based and consumption-based estimates, and using both national and sub-national data. Some other studies look 
at long-run growth rates of emissions and GDP for a large group of countries. Csereklyei and Stern (2015) use long-run growth rates for 93 countries and find weak decoupling, while Jakob et al. (2012) find that the average developing economy has experienced above-average growth of total $\mathrm{CO} 2$ emissions over the 1971-2005 period. Pao and Tsai (2010) show that the CO2 long-run elasticity with respect to real GDP is positive and statistically significant for China. There are some papers that have used Chinese provincial data. Narayan (2004) was among the first to exploit provincial data to analyze trend and cycles in real GDP fluctuations in China. Some subsequent papers have used provincial data for emissions, but have not maintained the distinction between trends and cyclical behavior emphasized in Narayan's work and in this paper. For instance, Auffhammer and Carson (2008) use provincial level data to forecast CO2 emissions for China, while Du et al. (2012) use it to analyze the driving forces of China's CO2 emissions. Wang et al (2014) study the extent of a convergence process of CO2 emissions within China and $\mathrm{Xu}$ and Lin (2015) show that there is an inverted U-shape relationship between industrialization and CO2 emissions in the three regions in China. Zhang et al. (2017) evaluates energy security at the provincial level and shows that all of them face threats related to energy availability and diversity. Very few studies have attempted to account for emissions from trade, with the exception of Mi et al. (2016).

The remainder of the paper is organized as follows. Section II discusses the paper's empirical approach, aggregate level data, and the baseline estimates of the Okun and Kuznets elasticities across a broad range of filtering techniques and data. Section III broadens the analysis by looking at a longer time horizon and discussing how these elasticities have changed over time. It also studies trends and cycles at the provincial level, providing evidence of lower Kuznets elasticities in richer provinces. The conclusion and policy implications of our findings are discussed in Section IV. Additional figures and tables are in the Appendix.

\section{Trends And CyCles AT The Aggregate LeVel}

\section{A. Empirical Approach}

To understand empirically the relationship between emissions and real GDP, we first consider the following specification:

$\Delta e_{t}=\alpha+\omega \Delta y_{t}+u_{t}$

where $\Delta e_{t}$ and $\Delta y_{t}$ are the growth rates of emissions and real GDP, respectively. We then depart from this specification to distinguish cycles from trends and thereby to shed light on the recent decoupling phenomena seen in several advanced economies. As in Cohen et al (2017), we refer to the relationship between detrended real GDP and emissions as the Environmental Okun's Law:

$e^{c}{ }_{t}=\beta^{\text {okun }} y^{c}{ }_{t}+\varepsilon^{c}{ }_{t}$

where $e^{c}{ }_{t}$ and $y^{c}{ }_{t}$ are the cyclical components of the $\log$ of emissions and $\log$ of real output,

respectively, and $\beta^{\text {okun }}$ is the Okun elasticity. We also consider the long-term relationship between 
emissions and real GDP by analyzing their respective trends. The Kuznets estimate, $\beta^{\text {kuznets }}$, relates trend real GDP, $y^{\tau}{ }_{t}$, with trend emissions, $e^{\tau}{ }_{t}$, such that:

$e^{\tau}{ }_{t}=\gamma+\beta^{\text {kuznets }} y^{\tau}{ }_{t}+\varepsilon^{\tau}{ }_{t}$

We estimate these equations for both national and provincial data. We estimate the model with an intercept $(\gamma)$, expecting provinces to be endowed with relatively different initial conditions and, therefore, with some inherent historical level of emissions.

To extract the cyclical and trend components for a generic variable $x_{t}$ (denoted $x^{c}{ }_{t}$ and $x^{\tau}{ }_{t}$, respectively) where $x_{t}=\left\{y_{t}, e_{t}\right\}$, we employ the commonly used Hodrick-Prescott (HP, 1981, 1997) filter. This filter minimizes the following function:

$\min _{\tau_{t}}\left\{\sum_{t=1}^{T}\left(x_{t}-x^{\tau}{ }_{t}\right)^{2}+\lambda \sum_{t=1}^{T}\left[\left(x^{\tau}{ }_{t}-x^{\tau}{ }_{t-1}\right)-\left(x^{\tau}{ }_{t-1}-x^{\tau}{ }_{t-2}\right)\right]^{2}\right\}$

Where $\lambda$ is the smoothing parameter set at 100, as common practice when employing annual data. ${ }^{1}$ The criticisms surrounding the use of the HP filter, in particular in the context of a large sample of very heterogeneous countries, are well-known (see Harvey and Jaeger, 1993; Cogley and Nason, 1995; Hamilton, 2017). We therefore also compare the cyclical and trend series with the ones proposed by Hamilton (2017) as an alternative filtering method. For that purpose, we estimate:

$x_{t+h}=\gamma_{0}+\sum_{j=0}^{k} \gamma_{j}+x_{t-j}+u_{t+h}$

where $x_{t}=x^{\tau}{ }_{t}+x^{c}{ }_{t}$. The non-stationary part of the regression provides the cyclical component:

$x^{c}{ }_{t}=\hat{u}_{t}$

while the trend is given by

$$
x^{\tau}{ }_{t}=\hat{\gamma}_{0}+\sum_{j=0}^{k} \hat{\gamma}_{j}+x_{t-h-j}
$$

Hamilton (2017) suggests that $h$ and $k$ should be chosen such that the residuals from equation (5) are stationary and points out that, for a broad array of processes, the fourth differences of a series are indeed stationary. We choose $h=2$ and $k=3$, which is line with the dynamics seen in both emissions and GDP. We also use the Baxter-King (BK; 1999) and Christiano-Fitzgerald (CF; 2003) band-pass

\footnotetext{
${ }^{1}$ Ravn and Uhlig (2002) suggest a smoothing parameter of 6.25 for annual data, which is more congruent with a smoothing parameter of 1600 applied to quarterly data and has commonly been applied to advanced economies' time series. The greater the value of $\lambda$, the larger is the penalty on variations of the trend's growth rate (i.e. the sum of the squares of the trend's second differences).
} 
filters. ${ }^{2} \mathrm{BK}$ derives a finite approximation to the infinite-order symmetric moving-average filter by estimating the cyclical component of a time series as:

$$
x^{c}{ }_{t}=\sum_{j=-k}^{k} \hat{\gamma}_{j} x_{t-j}
$$

where $\hat{\gamma}_{j}$ are the modified weights for a finite-order symmetric moving-average filter such that

$$
\sum_{j=-k}^{k} \hat{\gamma}_{j}=0, \hat{\gamma}_{j}=\gamma_{j}-\bar{\gamma}_{k} \text { and } \hat{\gamma}_{j}=\gamma_{-j} \text { with } \gamma_{j} \text { being the ideal weight in the time domain and } \bar{\gamma}_{k} \text {, its }
$$

mean truncated at $\pm k$. Removing the cyclical component of the time series $x_{t}$ provides the trend component $x^{\tau}{ }_{t}$. Similarly, CF derives a finite approximation to the ideal band-pass filter by minimizing the mean squared error between the filtered series and the series filtered by an ideal bandpass filter, with the cyclical component given by:

$x^{c}{ }_{t}=\gamma_{0} x_{t}+\sum_{j=1}^{T-t-1} \gamma_{j} x_{t+j}+\bar{\gamma}_{T-t} x_{T}+\sum_{j=1}^{t-2} \gamma_{j} x_{t-j}+\bar{\gamma}_{t-1} x_{1}$

where $\gamma_{0}, \gamma_{1}, \ldots$ are the weights used by the ideal band-pass filter and $\bar{\gamma}_{T-t}$ and $\bar{\gamma}_{t-1}$ are linear functions of the ideal weights. Equations (1), (2), and (3) are estimated using ordinary least squares (OLS) for the aggregate data for China as a whole and for each province.

\section{B. Data}

Our baseline analysis covers the period 1990-2012 and focuses on both CO2 emissions as well as GHG emissions. GHG emissions are aggregated by the World Resources Institute (WRI) by types of atmospheric gases (including $\mathrm{CO} 2$ and non- $\mathrm{CO} 2$ emissions, such as methane $(\mathrm{CH} 4)$, nitrous oxide (N2O), and fluorinated gases (F-gases)) according to their 100-year Global Warming Potential (GWP100) as per the IPCC's 2nd Assessment Report. CO2 emissions are taken from the International Energy Agency (IEA) and are derived from fossil fuel combustion and cement manufacture. $\mathrm{CH} 4$ and N2O are taken from both the U.S. Environmental Protection Agency (US-EPA) for industrial processes and waste, and from the Food and Agriculture Organization (FAO) for agricultural emissions. F-gas emissions are provided by the US-EPA and fall within the industrial processes sector. $\mathrm{CO} 2$ emissions account for the vast majority of emissions (more than 83 percent of total emissions), followed by methane at around 9 percent. The electricity sector is the major source of emissions (39 percent) and the manufacturing sector comes second with 24 percent of emissions.

In addition to these production-based emissions, we use consumption-based emissions that include the net emissions embodied in international trade. For that purpose, we adjust our GHG emissions

\footnotetext{
${ }^{2}$ Other methods exist, such as the one explored in Chang et al. (2015), which develops a Bayesian reduced-form method to split the series.
} 
to include the difference between consumption- and production-based emissions from the Eora multiregion input-output (MRIO) database. ${ }^{3}$ Given some discrepancies between WRI's emissions and Eora's emissions, we prefer to follow that strategy. Figure 1 shows both production- and consumption-based GHG emissions for our baseline sample period. China, as is the case for several other emerging and low income economies, has lower levels of emissions when net emissions from international trade are included than when only production-based emissions are accounted for. Real GDP (in national currency) and real GDP growth used for the baseline exercise are taken from the latest update of the IMFs World Economic Outlook (WEO) database, which starts in 1980.

Figure 1. Consumption- and Production-Based GHG Emissions

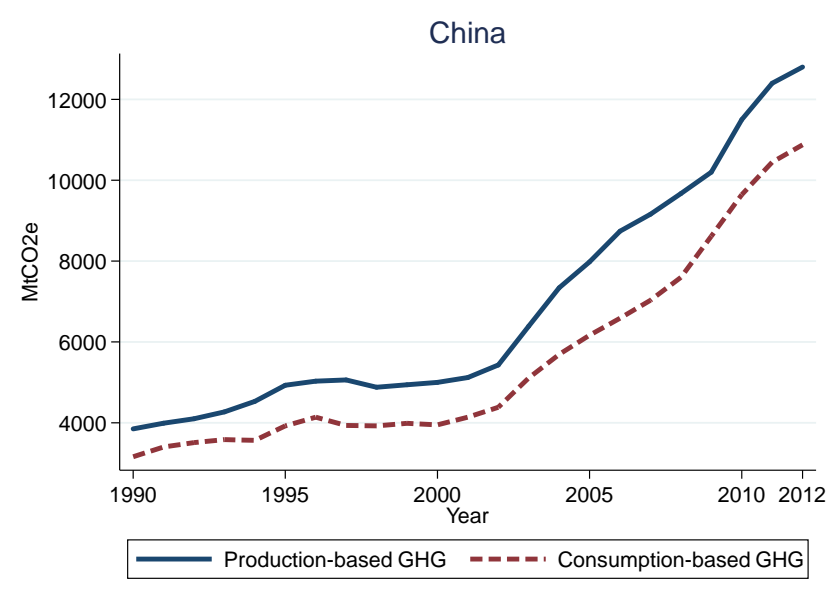

C. Baseline Results

This section provides a thorough robustness analysis of the alternative filtering methods used to extract the cyclical fluctuations from their trend components, contrasting the Okun and Kuznets elasticities derived from these filters. Figure 2 shows the cycles and trends extracted from the different filters for China's real GDP and production-based emissions. Despite the divergent peaks and troughs at the cyclical level, all filters depict trend real GDP to be steeper than trend emissions with the crossing around year 2000 signaling the rapid convergence of China's economy. There is thus no sign yet of a decoupling between emissions and growth at the aggregate level. A variance decomposition of emissions across the different filters - given by $\operatorname{var}\left(e_{t}\right)=\operatorname{var}\left(e^{c}{ }_{t}\right)+\operatorname{var}\left(e^{\tau}{ }_{t}\right)+2 \operatorname{cov}\left(e^{c}{ }_{t}, e^{\tau}{ }_{t}\right)-\operatorname{shows}$ that most of the variance in emissions is captured by the variance in trend emissions, with the relative contribution of the variance of the cyclical terms and the covariance between the trend and cyclical series being negligible.

Table 1 presents the Okun and Kuznets coefficients across the different filtering methods. Although several advanced economies have experienced a decoupling between trend real GDP and trend production-based emissions over the same sample period, China presents a positive and statistically

\footnotetext{
${ }^{3}$ Additional details about the database can be found in Lenzen et al. (2012) and (2013).
} 
significant environmental Kuznets elasticity of 0.59 . The alternative filtering methods used to estimate equation (3) point to a similar average coefficient, ranging from 0.51 to 0.66 with the $\mathrm{CF}$ and Hamilton filter respectively. This suggests China is yet to transition to a low carbon path. Analyzing the Kuznets residuals confirms that these are stationary, with the Augmented Dickey-Fuller test showing that we reject the hypothesis that residuals have a unit root (Figure A.1 and Table B.1 in the Appendix). Alternatively, the environmental Okun's coefficient from equation (2) suggests that emissions tend to be procyclical. However, the coefficient is less precisely estimated, ranging between 0.35 to 0.65 . Although the specification in growth rates tends to give a coefficient that differs more from its Okun or Kuznets elasticities, the estimated elasticity from equation (1) for China is fairly close to the elasticity implied by the trend relationship at 0.58 .

Figure 2. Trends and Cycles across Different Filtering Methods
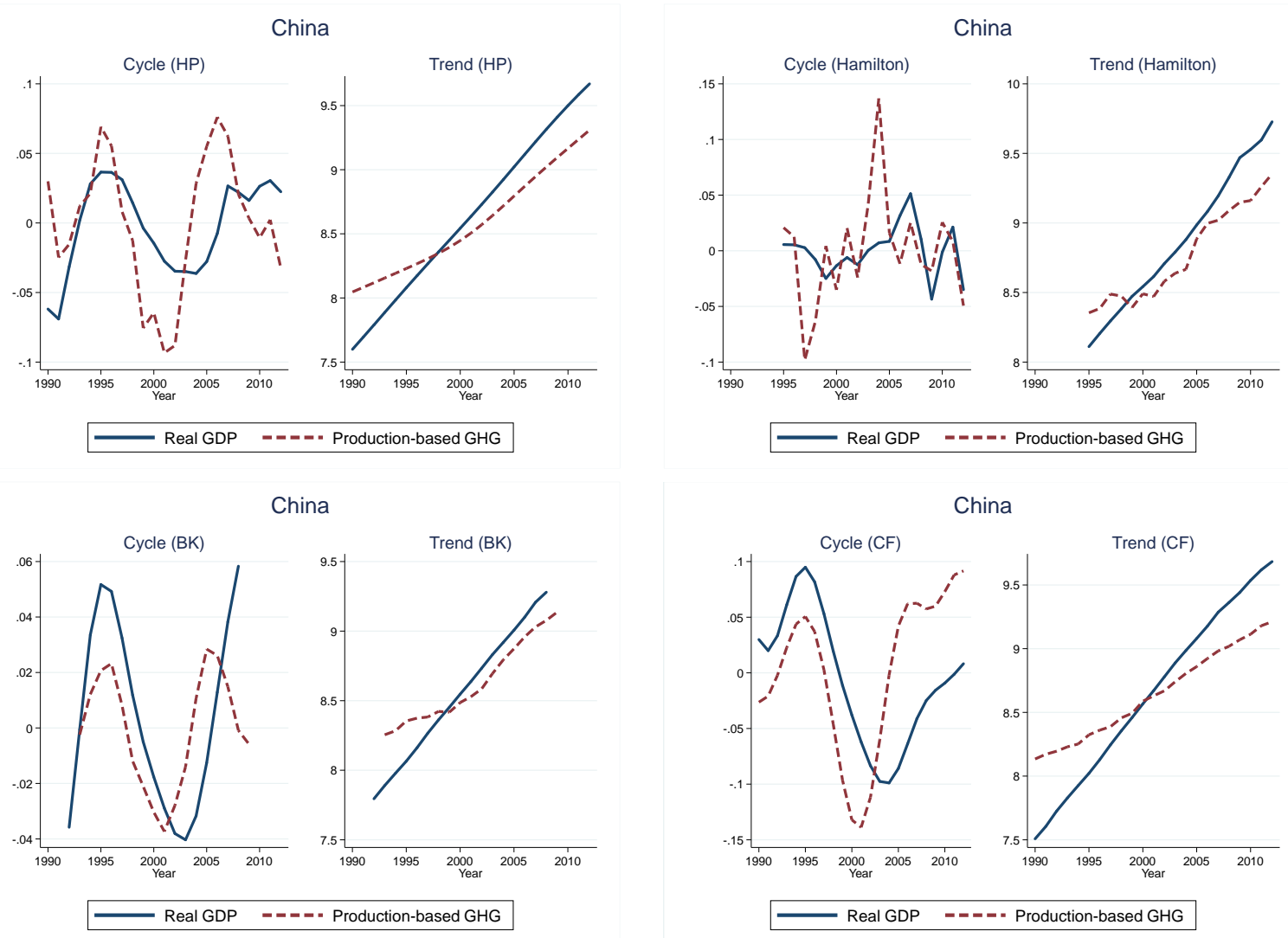

Using alternative measures of emissions confirms our baseline results as shows the bottom part of Table $1 .{ }^{4}$ The Kuznets elasticity derived from using $\mathrm{CO} 2$ emissions is larger than when methane and other greenhouse gases are included (0.68), which suggests that when trend GDP grows, trend CO2 emissions grow faster than other damaging gases; whereas the coefficient from adding emissions from Land-use and Land-use Change and Forestry (LULUCF), such as deforestation emissions, taken from FAO to our original GHG emissions is fairly similar to our baseline estimate. Despite China being one of the major exporter of carbon-intensive inputs, its consumption-based Kuznets coefficient shows that trend consumption-based emissions grow at a similar rate as its production-based emissions. This

\footnotetext{
${ }^{4}$ The HP filter was used to extract the cyclical and trend components of these time series.
} 
suggest that emissions embodied in trade are not an important driver of domestically-produced emissions. Figure 3 compares the cyclical and trend components of production- vs. consumption-based emissions, with these two types of emissions displaying a clear co-movement.

Table 1. Contrasting Elasticities at the Aggregate Level

\begin{tabular}{lll}
\hline \multicolumn{1}{c}{ China } & \multicolumn{1}{c}{$(1)$} & \multicolumn{1}{c}{$(2)$} \\
& \multicolumn{1}{c}{$\hat{\beta}^{\text {okun }}$} & $\hat{\beta}^{\text {Kuznets }}$ \\
\hline Growth rates, Production-based GHG (1990-2012) & 0.58 & - \\
Alternative Filtering Methods & & \\
Growth rates, Production-based CO2 (1990-2012) & $0.681^{* *}$ & - \\
HP filter, Production-based GHG (1990-2012) & $0.478^{*}$ & $0.591^{* * *}$ \\
Hamilton filter, Production-based GHG (1990-2012) & 0.648 & $0.655^{* * *}$ \\
BK filter, Production-based GHG (1990-2012) & $0.350^{* *}$ & $0.595^{* * *}$ \\
CF filter, Production-based GHG (1990-2012) & 0.365 & $0.512^{* * *}$ \\
\multicolumn{1}{c}{ Alternative Emissions Data } & & \\
Production-based CO2 (1990-2012) & 0.555 & $0.677^{* * *}$ \\
Production-based GHG with LULUCF (1990-2012) & 0.489 & $0.618^{* * *}$ \\
Consumption-based GHG (1990-2012) & $0.406^{*}$ & $0.581^{* * *}$ \\
Consumption-based CO2 (1990-2012) & $0.501^{* * *}$ & $0.552^{* * *}$ \\
\hline
\end{tabular}

Note: $* * * \mathrm{p}<0.01, * * \mathrm{p}<0.05, * \mathrm{p}<0.1$.

Figure 3. Trends and Cycles in Production- and Consumption-Based Emissions

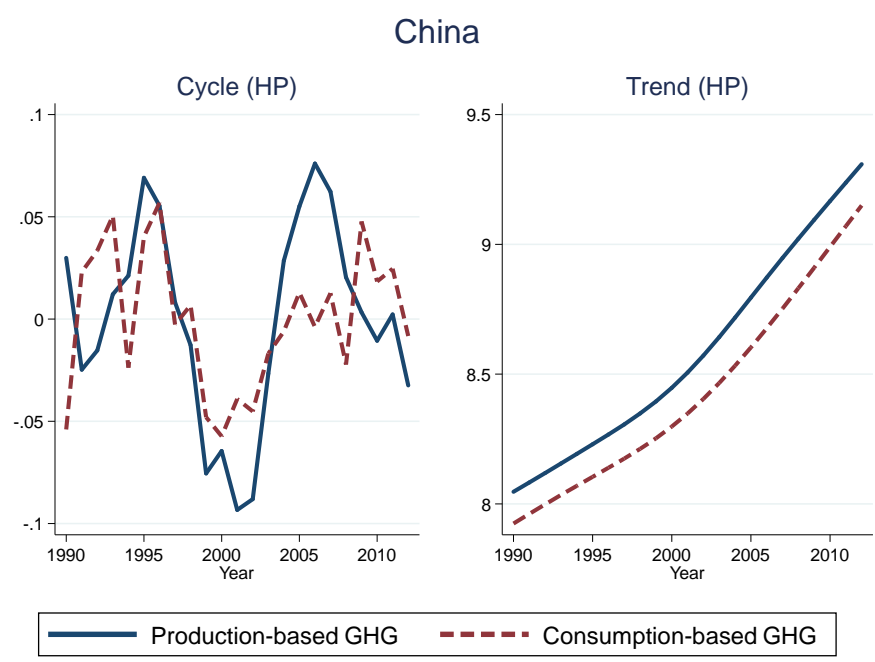

\section{Are Trends and Cycles Changing?}

Although China is the largest world GHG emitter, its economy is transitioning from the manufacturing of industrial goods and the extraction of carbon-intensive good to services and more high-end goods. As China gets richer - its real income per capita went from US\$309 in 1980 to US\$8,167 in 2015 - one would expect its emissions-output elasticity to decrease over time. The previous section looked at our 
baseline sample covering the 1990-2012 period, whereas this section explores whether longer time series can shed light on China's transition to a low-carbon path and whether there are signs of a decoupling between emissions and output. Looking at a few cases of advanced economies may foreshadow the steps the Chinese economy will experience in the future. Countries like France and Germany are worth exploring. These economies had Kuznets elasticities in the post-WWII period (1946-1982) above 0.6, before experiencing a sharp decrease in the carbon-intensity of their production during the Great Moderation period with the emergence of production of electricity from nuclear power - for which Kuznets elasticities went negative for Germany (-0.7, a complete decoupling between GDP and emissions) and reduced significantly for France (to 0.15).

\section{A. A Longer Time Horizon Perspective}

The availability of longer time series allows us to have a more accurate picture of how the relationship between emissions and GDP has evolved, and thus assess whether the Okun and Kuznets elasticities have changed over time. For that purpose, this analysis draws on CO2 emissions starting from 1902 to 2012, taken from the Carbon Dioxide Information Analysis Center (CDIAC) and derived from fossil fuel combustion. Real GDP is taken from the Maddison-Project (in 1990 international dollars), which covers the period 1950-2009. Although CO2 emissions are the same for the 1990-2012 period as our baseline sample, real GDP figures differ from the IMF's WEO. Our first exercise is to split the time series into two periods, apply the filtering method, and estimate equations (2) and (3) for subsamples covering the post-WWII period (1950-1982) as well as the Great Moderation (1983-2007). Table 2 presents the Okun and Kuznets elasticities across the different periods. The first row presents the Okun and Kuznets coefficients for the entire 1950-2009 period. Both are statistically significant and above unity, capturing the average effect over the period. However, splitting the sample suggests the coefficient have changed substantially over time. Although China's emergence as an economic superpower is a much more recent phenomenon, the post-WWII period was a period of very high carbon-intensity of output. The Kuznets coefficient is three times larger than the elasticity obtained from our baseline analysis, i.e. one unit increase in China's real output adds almost twice as much units of CO2. The Great Moderation and China's opening to the world economy is concurrent with a lower Kuznets coefficient tending to our baseline result (0.73 vs. 0.68).

Across the business cycle the Okun elasticities are statistically significant and closer to unity than previously, which suggests that emissions have become less procyclical. The Okun coefficient decreased from 1.16 to 0.77 over the two periods. We also contrast the effect of output on emissions in periods of boom versus bust by estimating:

$e^{c}{ }_{t}=\beta^{\text {okun,boom }} y_{t}^{c, \text { boom }}+\beta^{\text {okun,bust }} y_{t}^{c, \text { bust }}+\varepsilon^{c}{ }_{t}$

where $y_{t}^{c, \text { boom }}$ is $y_{t}{ }^{c}$ from equation (2) when cyclical GDP is above trend (i.e. positive) and 0

otherwise, and $y_{t}^{c, b u s t}$ is given by $y_{t}{ }^{c}$ when it is below trend (i.e. negative) and 0 otherwise. Table 2 shows these estimates. Although not as precisely estimated as for the subsamples discussed above, China's emissions-output elasticity is greater during expansionary phases of the business cycle than it is during contractions - stronger and statistically significant for the 1950-2009 period. This result is 
in contrast with Sheldon (2017) and Cohen et al. (2017), which shows that for the U.S. and several other advanced and emerging economies, emissions tend to fall more during recessions than they increase during booms.

Table 2. Long-Run Elasticities at the Aggregate Level

\begin{tabular}{|c|c|c|}
\hline China & $\begin{array}{c}(1) \\
\hat{\beta}^{o k u n}\end{array}$ & $\begin{array}{c}(2) \\
\hat{\beta}^{\text {Kuznets }}\end{array}$ \\
\hline Production-based CO2 (1950-2009) & $1.200 * * *$ & $1.040 * * *$ \\
\hline Post-WWII, Production-based CO2 (1950-1982) & $1.158 * *$ & $1.875^{* * *}$ \\
\hline Great Moderation, Production-based CO2 (1983-2007) & $0.774 * * *$ & $0.732 * * *$ \\
\hline Boom, Production-based GHG (1990-2012) & 0.742 & - \\
\hline Boom, Production-based CO2 (1950-2009) & $2.134 * * *$ & - \\
\hline Bust, Production-based GHG (1990-2012) & 0.335 & - \\
\hline Bust, Production-based CO2 (1950-2009) & 0.469 & - \\
\hline
\end{tabular}

Note: $* * * \mathrm{p}<0.01, * * \mathrm{p}<0.05, * \mathrm{p}<0.1$.

\section{B. A Provincial Level Perspective}

China is a large economy and looking at the country as whole may reveal little information about the extent of the decoupling between emissions and GDP, since it may obfuscate important trends and cycles at the provincial level. Provinces have changed enormously over the last two decades. Provinces from the eastern region have relatively high real incomes and their local governments are more endowed relative to the less developed central and western regions of China - Narayan et al. (2008) do not find evidence that as real income increases in those regions, their public sector expands. For instance, real GDP per capita in the eastern provinces of Beijing, Shanghai, and Tianjin tripled between 1995 and 2010, reaching levels above 71,000 RMB (above US\$10,000). By contrast, most central and western provinces still have real incomes per capita around RMB 25,000 (or less than US\$4,000). And the disparities go beyond income per capita as pointed out by Bao et al. (2002) and Yang (2002), among others.

The regional analysis covers 29 provinces over the 1995-2009 period. CO2 emissions are taken from Du et al. (2012), while real GDP is retrieved from the National Bureau of Statistics of China.

$\mathrm{CO} 2$ emissions from fossil fuel burning and cement production are compiled from the regional energy balances in the China Energy Statistical Yearbook, with emissions factors taken from the IPCC $2^{\text {nd }}$ Assessment Report (2006). CO2 emissions from fossil fuel burning, covering coal, coke, gasoline, kerosene, diesel, fuel oil, and natural gas, are given by $e_{t}=\sum_{i \in S} c_{i, t} \times f_{i}$, where $c_{i, t}$ is the consumption of fuel $\mathrm{i}$ (with the exception of cement, for which the production is used) and $f_{i}$ is the emission factor of fuel i, for $\mathrm{S}=$ \{coal, coke, gasoline, kerosene, diesel, fuel oil, natural gas, cement $\}$. Note that these are (approximately) consumption-based emissions since the authors adjusted the level of emissions produced by the emissions embodied in interprovincial electricity trade. This reduces the emissions from western provinces, rich in coal, in favor of coastal provinces that are net importers of electricity. 
Figures 4, 5, and 6 display the trend and cyclical components of real GDP and CO2 emissions, extracted using the HP filter, of the provinces in the Eastern, Central, and Western regions of China. Although the synchronization between emissions and output is not visible for most provinces across the business cycle, trend emissions and GDP do seem to co-move with little evidence of decoupling. The variance decomposition of each provinces' emissions show that, with the exception of the BK filter, most of the variance in emissions is captured by the variance in trend emissions. Figure A.2 presents the residuals from equation (3) for each province across the four different filters. It shows that the Kuznets residuals are overall stationary and thus the Kuznets elasticities do not reflect a spurious relationship between trend emissions and trend output.

\section{Figure 4. Trends and Cycles in the Eastern Region}
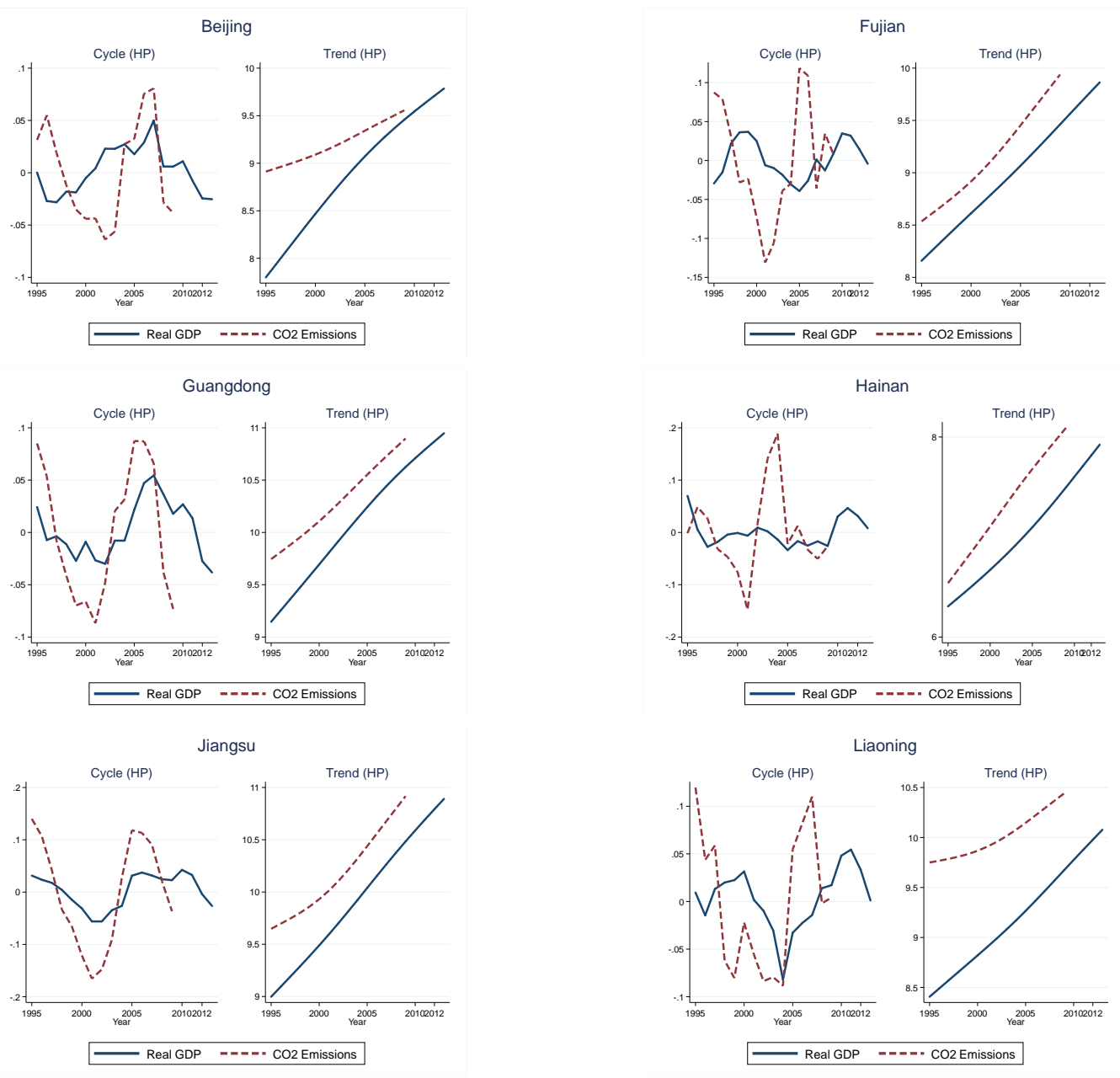

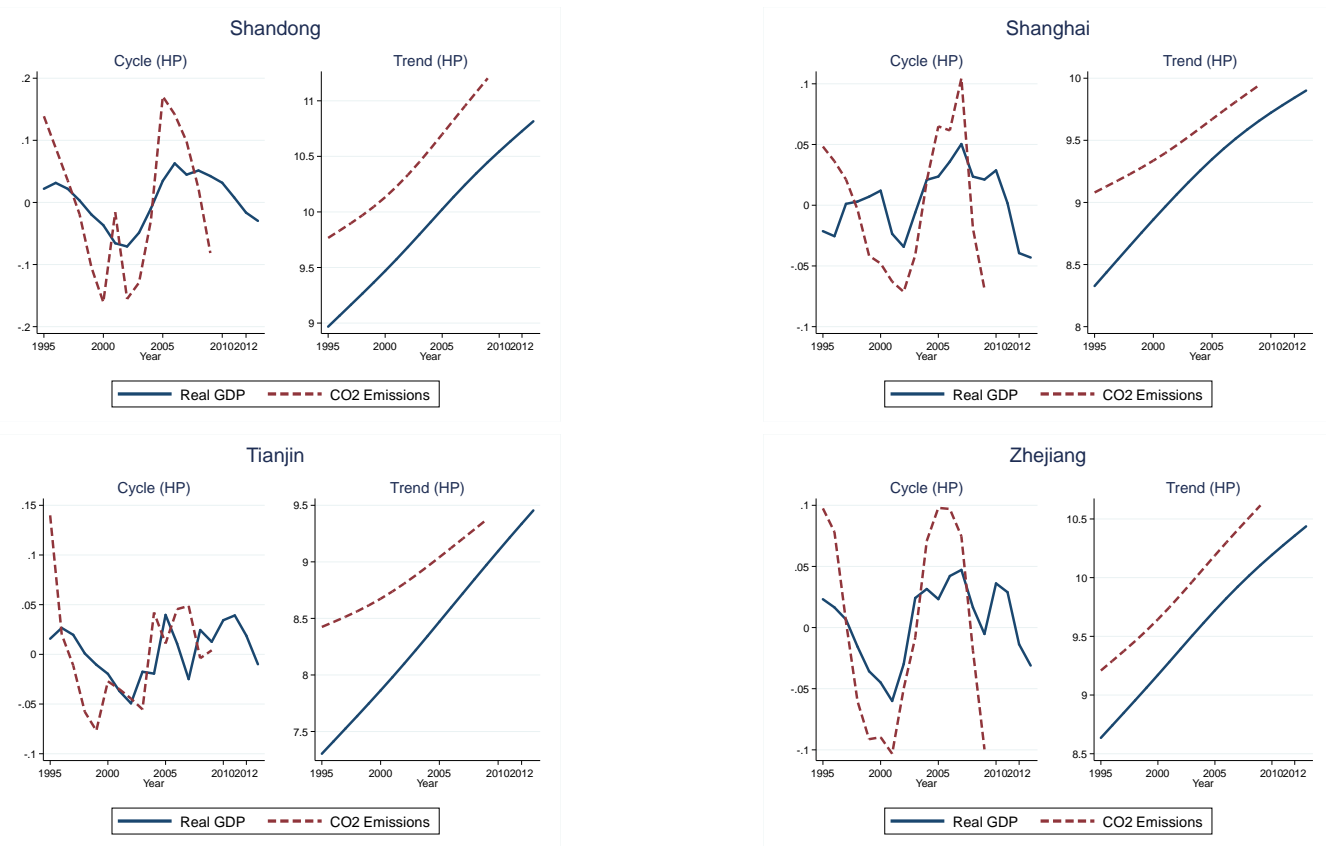

Figure 5. Trends and Cycles in the Central Region
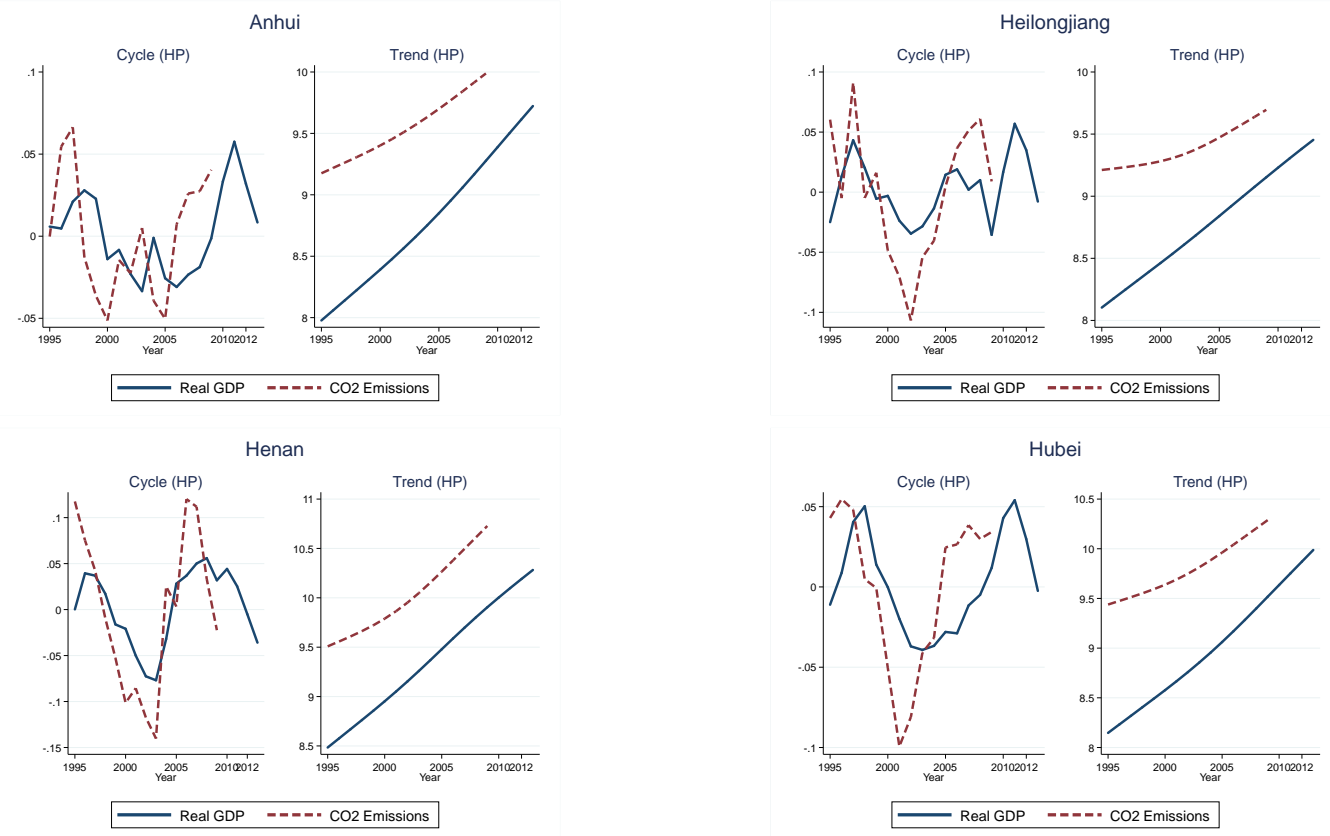

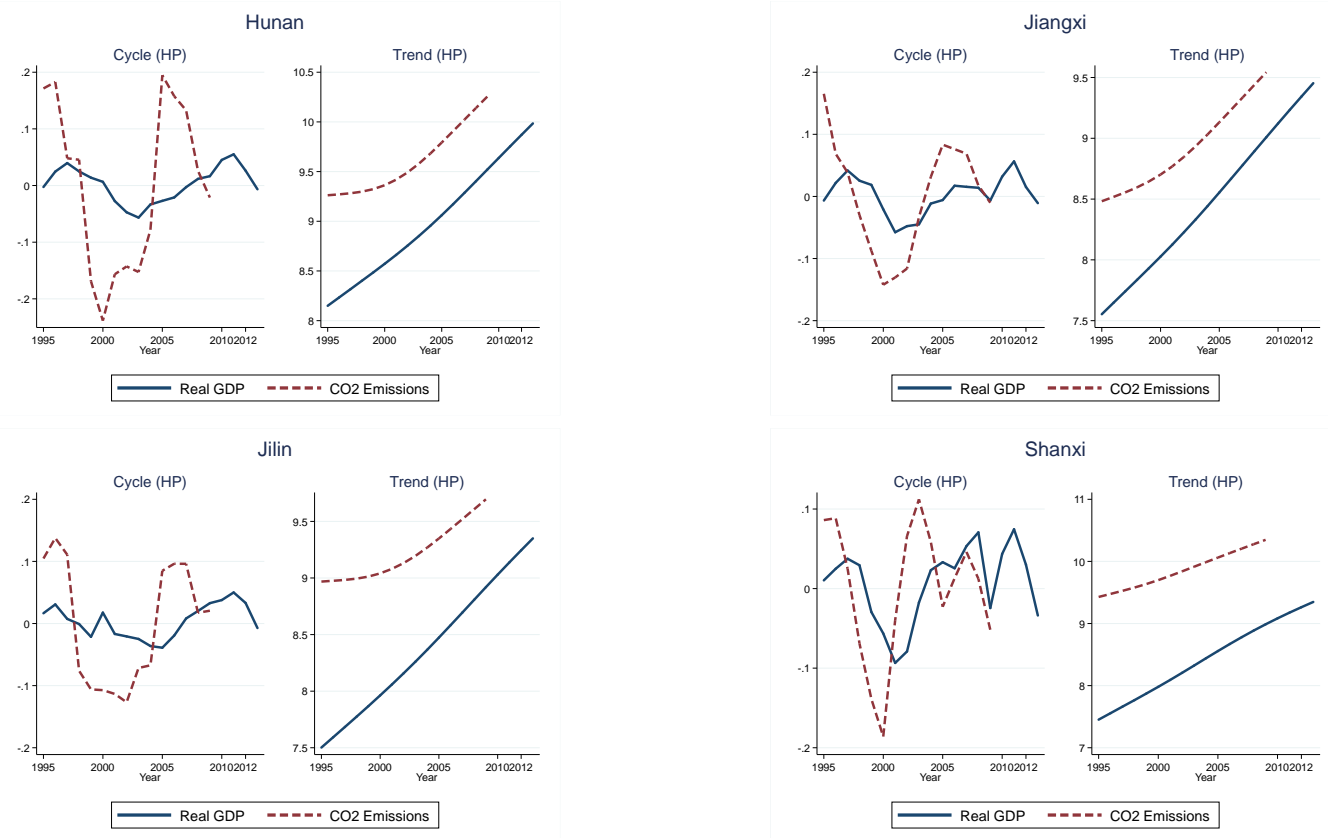

Figure 6. Trends and Cycles in the Western Region
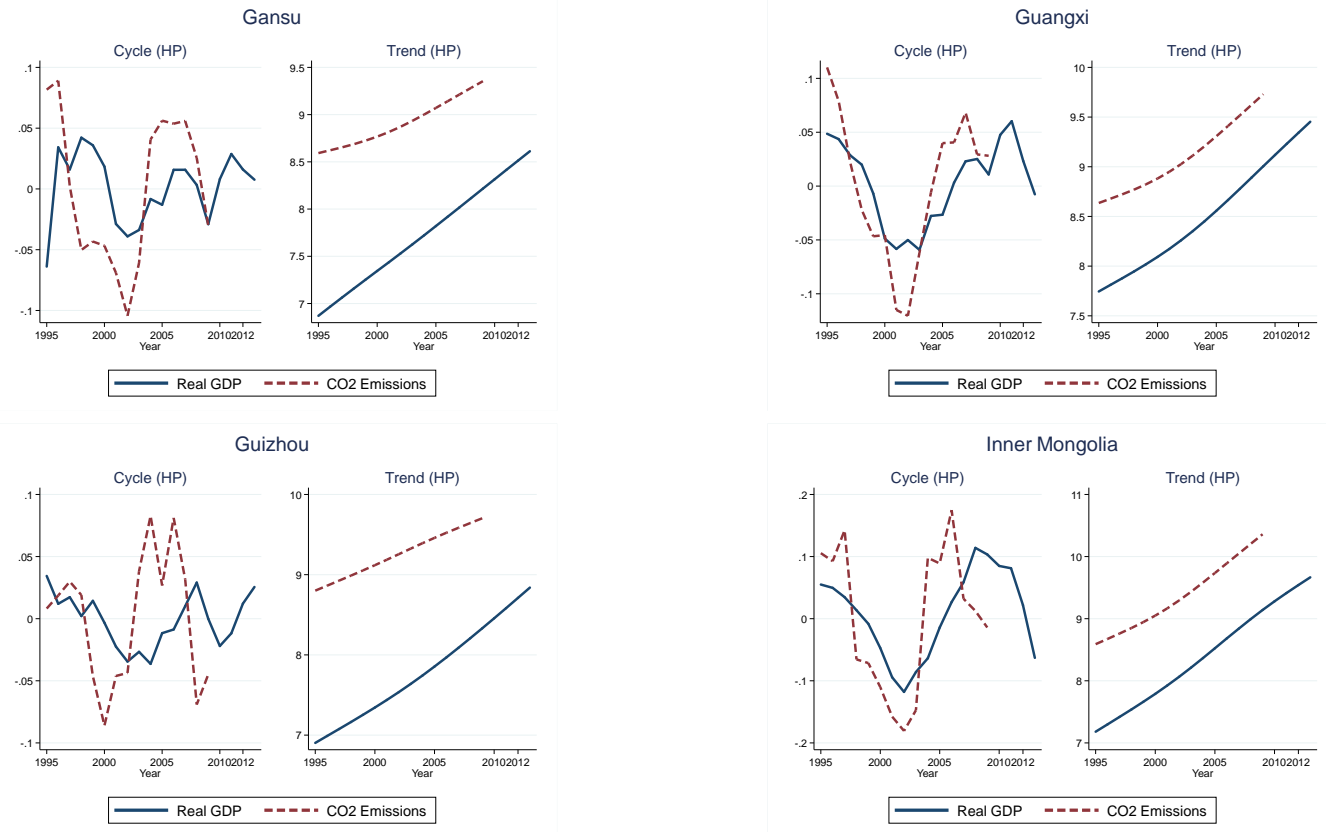

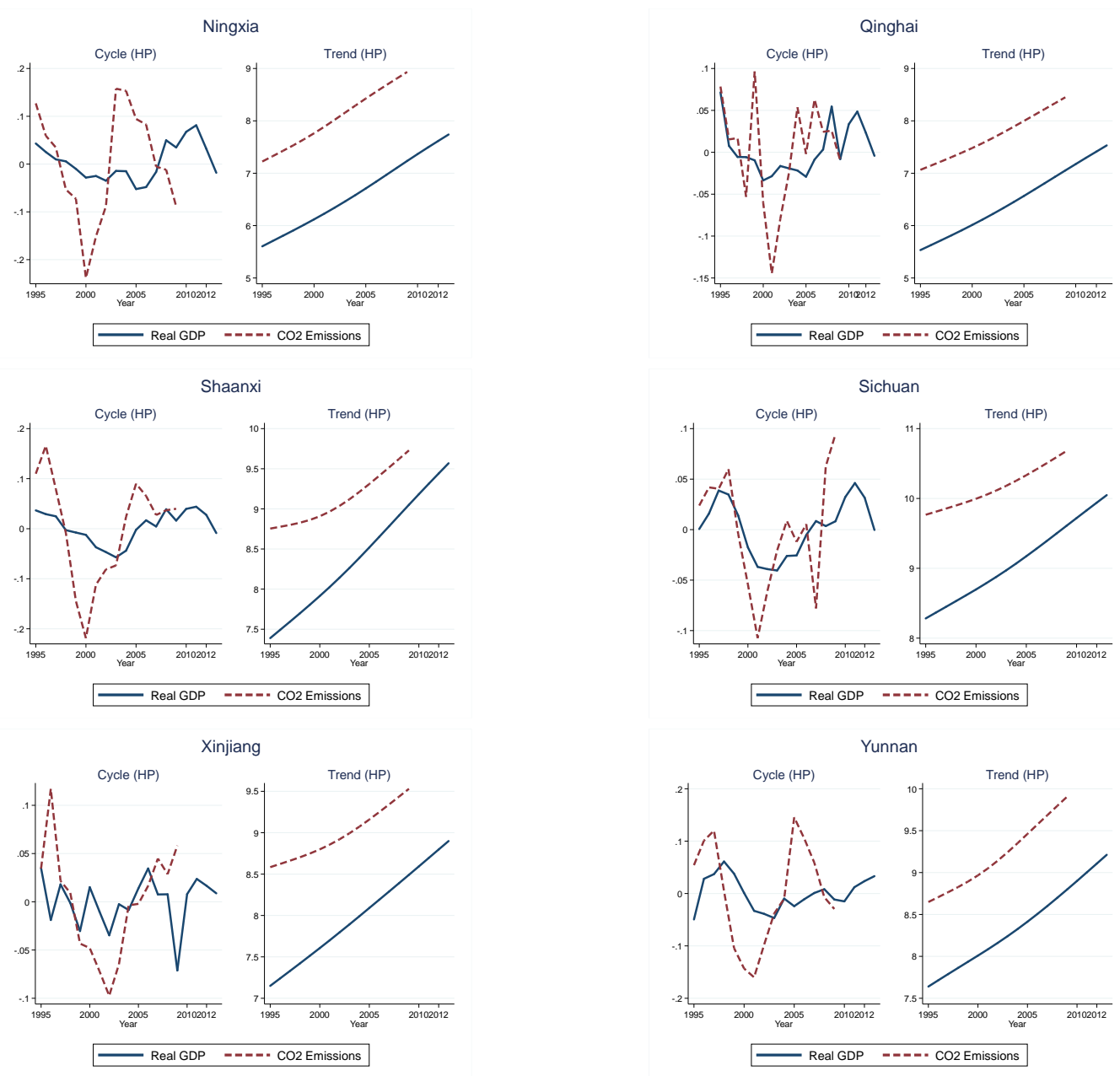

Table 3 as well as Figures A.3 and A.4 confirm the previous figures. The mean Kuznets coefficient across all provinces is close to 0.8. An increase in GDP in the provinces in the Center region is associated with a lower increase in emissions than in other regions, while for provinces like Fujian, Hainan, Ningxia, and Yunnan trend emissions tend to grow at a faster rate than GDP. This result is robust to alternative filters; these provinces tend to have the largest Kuznets elasticities across the different filtering methods as show Table 3 and B.2. On the other hand, Beijing shows some sign of a decoupling (or a lesser coupling, for lack of a better word) with Kuznets coefficients around 0.3 to 0.4.

Although the elasticities derived from the changes version of the model (equation (1)) tend to be less precisely estimated, they are closer to their Okun counterparts rather than their respective Kuznets elasticities. Over the business cycle, several provinces have emissions growing faster than GDP (Jiangsu, Shaanxi, Zhejian have statistically significant Okun coefficients above 2). While aggregate emissions tended to increase more in booms than in recessions, this is only the case for a few provinces. Carbon-intensive growth spells are discernible for Guangxi, Jiangsu, and Shaanxi, while provinces such as Guangdong, Henan, Inner Mongolia, Jiangxi, and Shandong see their emissions decrease more in recessions than they would increase during booms. 
Table 3. Okun and Kuznets Elasticities at the Provincial Level

\begin{tabular}{|c|c|c|c|c|c|c|c|}
\hline China & $\begin{array}{l}(1) \\
\widehat{\omega}\end{array}$ & $\begin{array}{c}(2) \\
\hat{\beta}_{h p}^{\text {okun }}\end{array}$ & $\begin{array}{c}(3) \\
\hat{\beta}_{h p}^{\text {Kuznets }} \\
\end{array}$ & $\begin{array}{c}(4) \\
\hat{\beta}_{\text {ham }}^{\text {Okun }} \\
\end{array}$ & $\begin{array}{c}(5) \\
\hat{\beta}_{\text {ham }}^{\text {Kuznets }} \\
\end{array}$ & $\begin{array}{c}(6) \\
\hat{\beta}_{h p}^{\text {okun,boom }}\end{array}$ & $\begin{array}{c}(7) \\
\hat{\beta}_{h p}^{\text {Okun,bust }}\end{array}$ \\
\hline \multicolumn{8}{|c|}{ Region: East } \\
\hline Beijing & 0.419 & 0.42 & $0.39 * * *$ & -0.67 & $0.286^{* *}$ & 0.761 & -0.416 \\
\hline Fujian & -1.402 & -1.29 & $1.10 * * *$ & -1.579 & $1.366^{* * *}$ & -0.782 & -1.692 \\
\hline Guangdong & $1.678 * * *$ & $1.40 * *$ & $0.78 * * *$ & 0.034 & $0.588 * * *$ & $1.138^{*}$ & $2.166 * *$ \\
\hline Hainan & 0.121 & 0.21 & $1.32 * * *$ & 2.006 & $1.097 * * *$ & 0.124 & 0.319 \\
\hline Hebei & 1.199 & $1.64 * *$ & $0.93 * * *$ & 0.74 & $0.974 * * *$ & 1.899 & 1.479 \\
\hline Jiangsu & $2.671 * * *$ & $2.71 * * *$ & $0.87 * * *$ & $1.219 *$ & $0.987 * * *$ & $2.816^{* * * *}$ & $2.641 * * *$ \\
\hline Liaoning & 1.101 & 0.22 & $0.56 * * *$ & $1.119 *$ & $0.685^{* * *}$ & -0.719 & 0.476 \\
\hline Shandong & $2.355^{* *}$ & $1.84 * * *$ & $0.98 * * *$ & 1.228 & $0.873 * * *$ & $1.729 * *$ & $1.961 * *$ \\
\hline Shanghai & $1.012 *$ & $1.00 *$ & $0.65 * * *$ & 0.715 & $0.488 * * *$ & 1.105 & 0.773 \\
\hline Tianjin & -0.189 & 0.76 & $0.58 * * *$ & 0.212 & $0.649 * * *$ & 0.882 & 0.672 \\
\hline Zhejiang & $1.701 * * *$ & $2.07 * * *$ & $0.96 * * *$ & $0.404 *$ & $0.845^{* * *}$ & $2.097 * * *$ & $2.038 * * *$ \\
\hline \multicolumn{8}{|c|}{ Region: Center } \\
\hline Anhui & 0.347 & 0.25 & $0.63 * * *$ & $-0.493^{*}$ & $0.819 * * *$ & 0.263 & 0.251 \\
\hline Heilongjiang & 0.957 & $1.40 * *$ & $0.47 * * *$ & 0.226 & $0.657 * * *$ & $1.686^{*}$ & $1.217 *$ \\
\hline Henan & $1.306^{*}$ & $1.51 * * *$ & $0.87 * * *$ & $1.184 * * *$ & $0.714 * * *$ & $1.304 * *$ & $1.673 * * *$ \\
\hline Hubei & $0.896 *$ & $0.75^{*}$ & $0.63 * * *$ & -0.664 & $0.818 * * *$ & 0.67 & 0.798 \\
\hline Hunan & 1.427 & 1.38 & $0.76^{* * *}$ & -1.095 & $0.492 *$ & 1.042 & 1.518 \\
\hline Jiangxi & 1.135 & $1.55^{* *}$ & $0.75 * * *$ & 0.007 & $0.917 * * *$ & 0.848 & $1.882 * *$ \\
\hline Jilin & 1.337 & 1.55 & $0.53 * * *$ & 0.023 & $0.607 * * *$ & 2.14 & 1.186 \\
\hline Shanxi & 0.411 & 0.56 & $0.61 * * *$ & 0.489 & $0.587 * * *$ & 0.478 & 0.62 \\
\hline \multicolumn{8}{|c|}{ Region: West } \\
\hline Gansu & 0.353 & 0.22 & $0.58 * * *$ & 0.247 & $0.597 * * *$ & 0.067 & 0.314 \\
\hline Guangxi & $1.244 * * *$ & $1.48 * * *$ & $0.88 * * *$ & 0.536 & $0.880^{* * *}$ & $1.734 * * *$ & $1.356^{* * *}$ \\
\hline Guizhou & -0.828 & -0.52 & $0.64 * * *$ & -0.168 & $0.451 * * *$ & -0.465 & -0.561 \\
\hline $\begin{array}{l}\text { Inner } \\
\text { Mongolia }\end{array}$ & $1.183^{*}$ & $0.95 * *$ & $0.91 * * *$ & $1.435^{*}$ & $0.939 * * *$ & 0.604 & $1.282 * *$ \\
\hline Ningxia & 0.921 & 0.29 & $1.07 * * *$ & 0.645 & $1.005 * * *$ & 0.529 & 0.11 \\
\hline Qinghai & 0.964 & $1.04 *$ & $0.92 * * *$ & 0.54 & $1.037 * * *$ & 0.885 & 1.345 \\
\hline Shaanxi & $1.650^{*}$ & $2.08 * *$ & $0.60 * * *$ & 0.873 & $0.797 * * *$ & $2.888 * *$ & $1.639 *$ \\
\hline Sichuan & $1.418^{*}$ & $1.35^{* *}$ & $0.69 * * *$ & 0.009 & $1.110 * * *$ & 1.394 & $1.321 * *$ \\
\hline Xinjiang & -0.334 & 0.11 & $0.71 * * *$ & 0.147 & $0.958 * * *$ & 0.603 & -0.097 \\
\hline Yunnan & 0.281 & 0.48 & $1.12 * * *$ & -1.423 & $1.222 * * *$ & 0.469 & 0.485 \\
\hline
\end{tabular}

The original EKC hypothesis suggested by Grossman and Krueger (1991, 1995), which relates the level of environmental degradation with per capita income, serves as a background for Figure 7. The figure relates the elasticities derived from the trend relationship between emissions and GDP with real income per capita at the beginning of our sample (1995). It suggests the existence of an inverted U-shaped relationship, i.e. richer provinces show mild signs of a decoupling. Contrasting the mean 
Kuznets elasticities for Chinese provinces and U.S. states by income per capita quintiles as depicts Figure 8 shows that despite the improvements suggested by the Figure 7, richer provinces still have much larger elasticities on average than the richer U.S. states, where signs of decoupling are clearer. Figure A.5 relates provinces' Okun and Kuznets elasticities with the size of their agricultural, industrial, and services GDP in 1995. While across the business cycle provinces with larger industrial sectors tend to have greater Okun coefficients, at the trend level that relationship gets blurred given the relatively homogeneous fraction of the industrial sector in provinces' GDP. On the other hand, provinces with larger agricultural sectors tend to have greater Kuznets elasticities.

Figure 7. Kuznets Elasticities and Real GDP Per Capita across Chinese Provinces

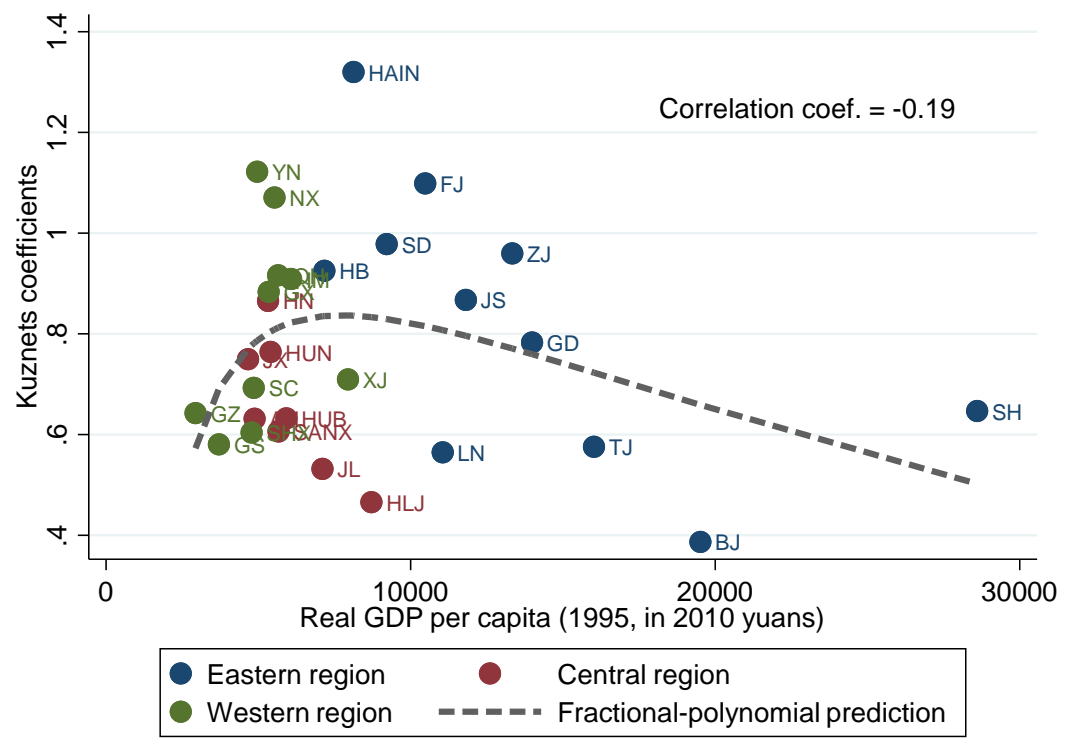

Figure 8. China's Provinces and U.S. States mean Kuznets Elasticities by Inter-Quintiles Ranges

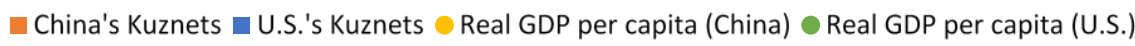

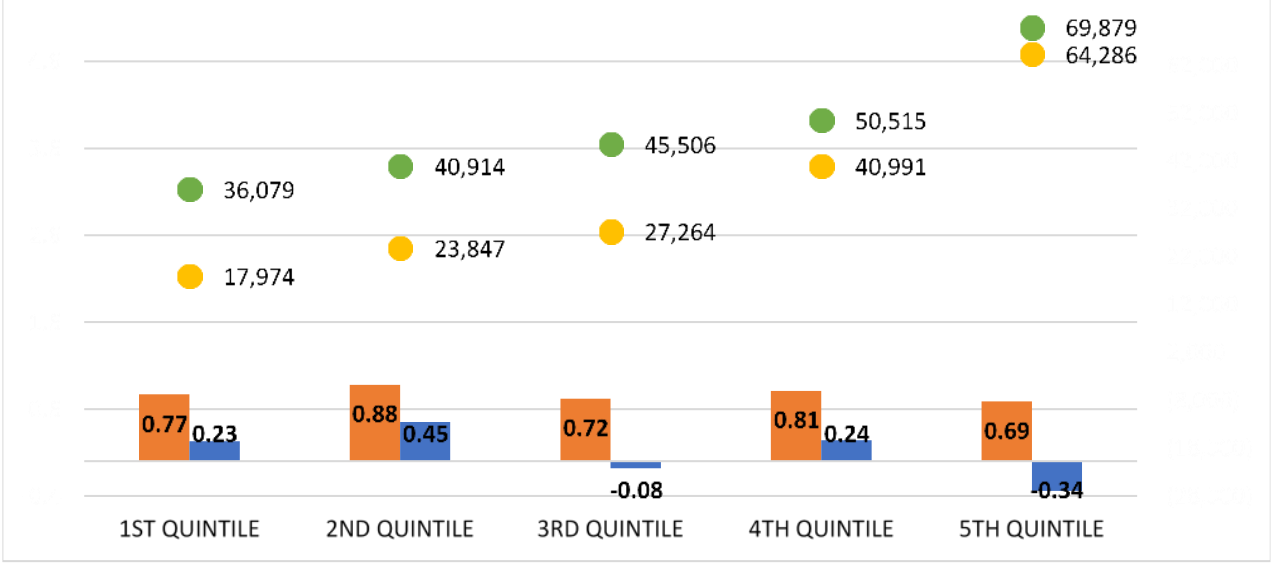




\section{CONCLUSION}

This paper assesses the extent of the decoupling between emissions and real GDP for China and its provinces by decomposing both series into their trend and cyclical components. Focusing on the trend relationship, we see little evidence of a decoupling at the aggregate level. However, there has been improvement over time. The Kuznets elasticity - the relationship between trend emissions and trend GDP - was three times higher during the three decades of the 1950s to 1970s than in the three decades since China opened up to the world and enjoyed a sharp rise in per capita GDP. This holds out the hope that further gains in per capita GDP will lead to even lower Kuznets elasticities (i.e. further progress toward decoupling).

It is true that the Kuznets elasticities for production-based emissions is somewhat bigger than that for consumption-based emissions. But the quantitative difference is not large and suggests that China's role in the world trading system need not be a big barrier to its ability to reduce emissions growth.

We also show that using provincial level data is a good source of further evidence on the prospects for decoupling. Although most of the provinces have positive Kuznets elasticities, we show that richer provinces (measured in real income per capita terms) tend to have lower Kuznets elasticities. A similar pattern holds for U.S. states, a comparison that is worth exploring further in future research.

We show that the Environmental Okun's Law holds in China and is asymmetric: emissions go up more during booms than they decline during busts. The Okun elasticities differ across provinces but understanding the drivers of these differences requires further research.

To summarize, giving the size of China's economy, aiming to put the country on a sustainable carbon trajectory requires a much more disaggregated look than has been the case in previous research. Indeed, signs of the decoupling between emissions and GDP are likely to start emerging at the provincial level. At a time when subnational entities are taking the lead in tackling climate change (such as recently with U.S. states and cities, following the federal decision to pull out of the Paris Agreement), these results point to provinces where low-carbon policies could be more effective. Policies taming emissions during business cycle upswings could further contribute to achieving China's intended emissions target.

In future work, it would be interesting to link changes in the Kuznets elasticity to the rebalancing of the Chinese economy. In particular, one could explore to what extent the transition from manufacturing to services had contributed to decoupling growth and GHG emissions. The province-level analysis used in this paper could be well suited for such a question. 


\section{APPENDIX FIGURES}

Figure A.1. Kuznets Residuals at the Aggregate Level

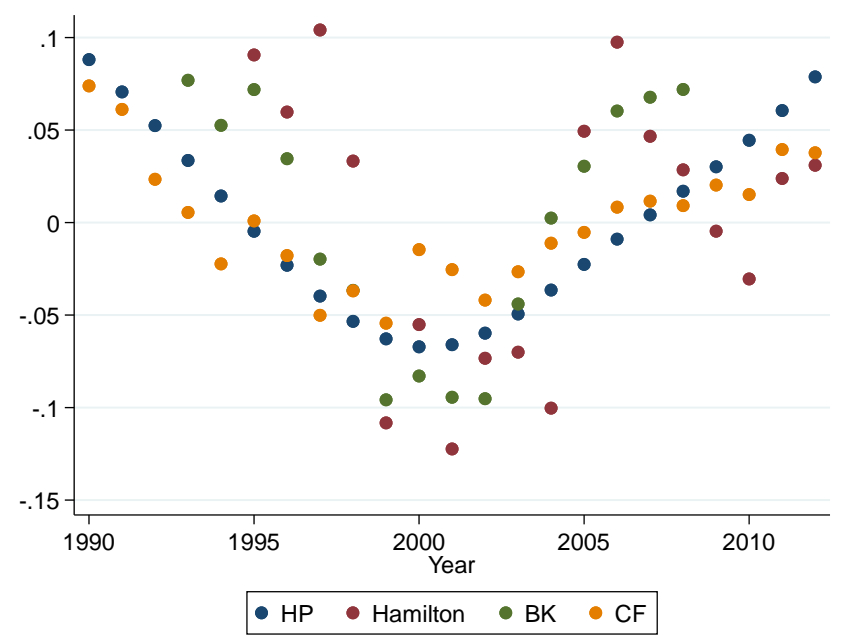

Figure A.2: Kuznets Residuals at the Provincial Level

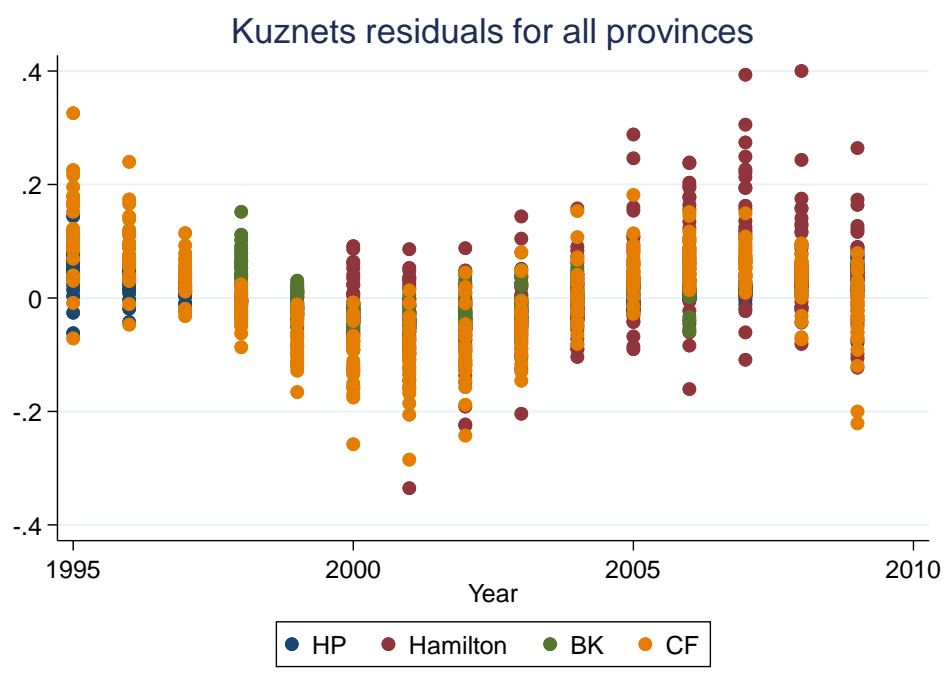


Figure A.3. Okun Elasticities across Chinese Provinces

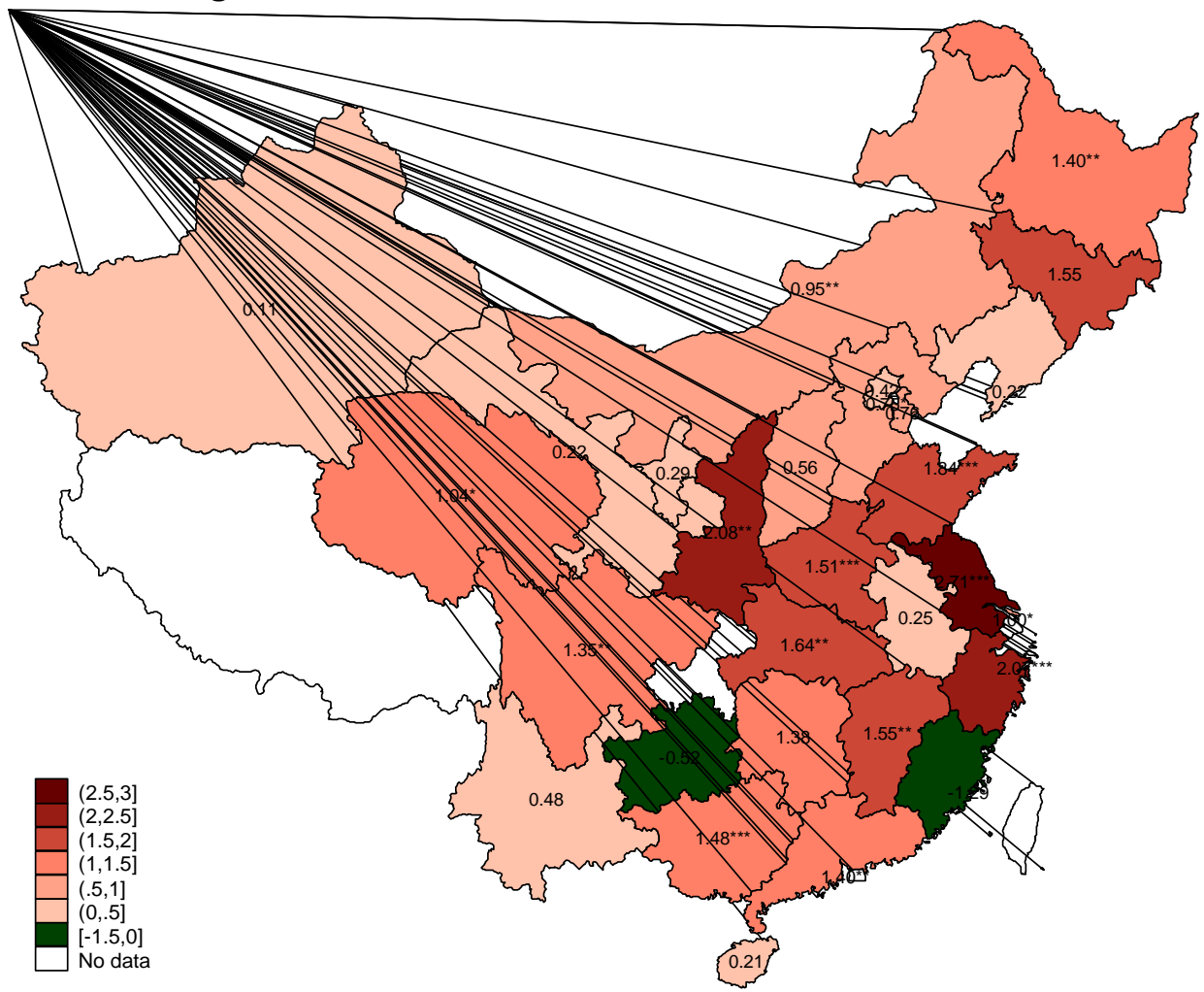

Figure A.4. Kuznets Elasticities across Chinese Provinces

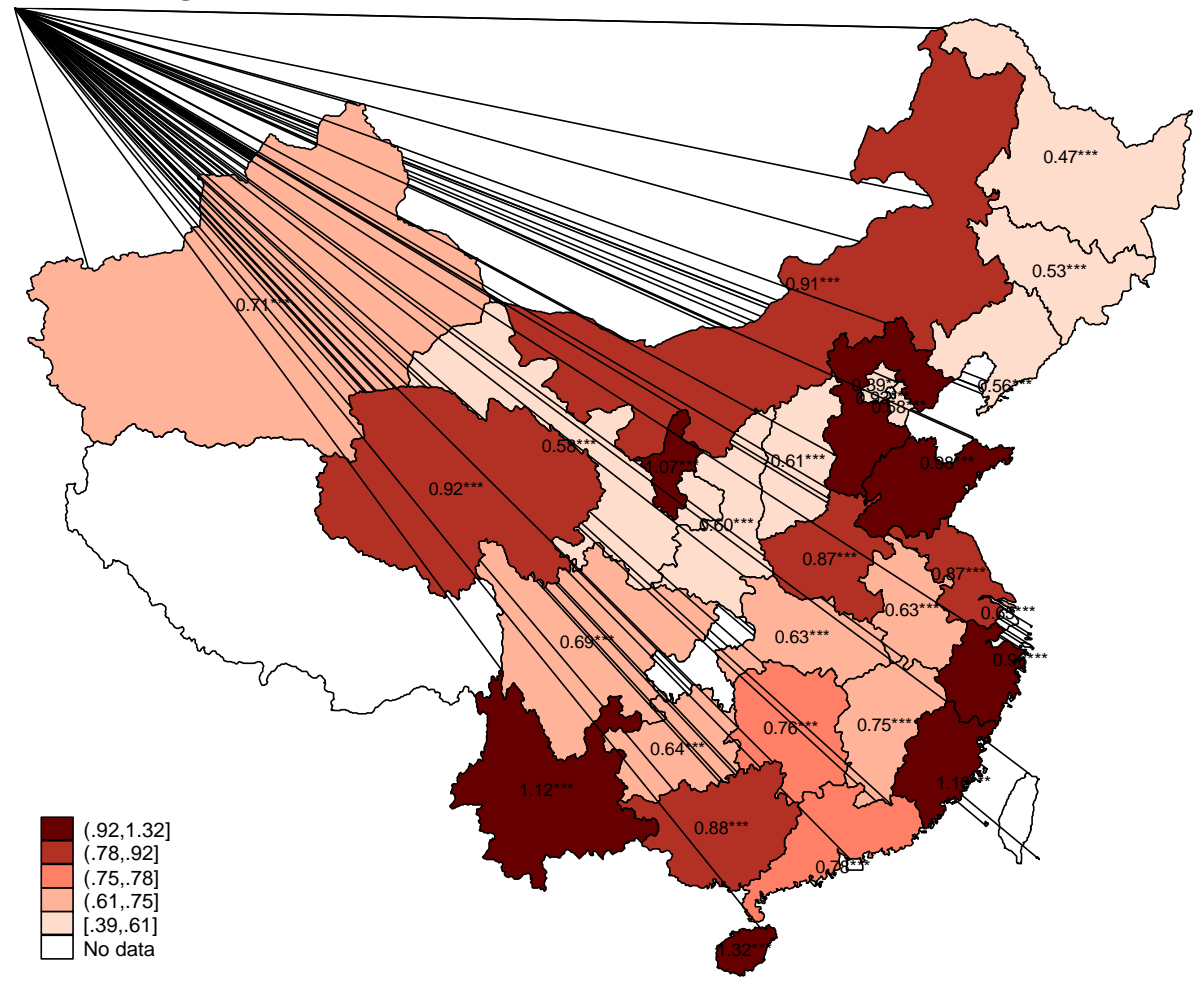


Figure A.5. Elasticities and Economic Structure
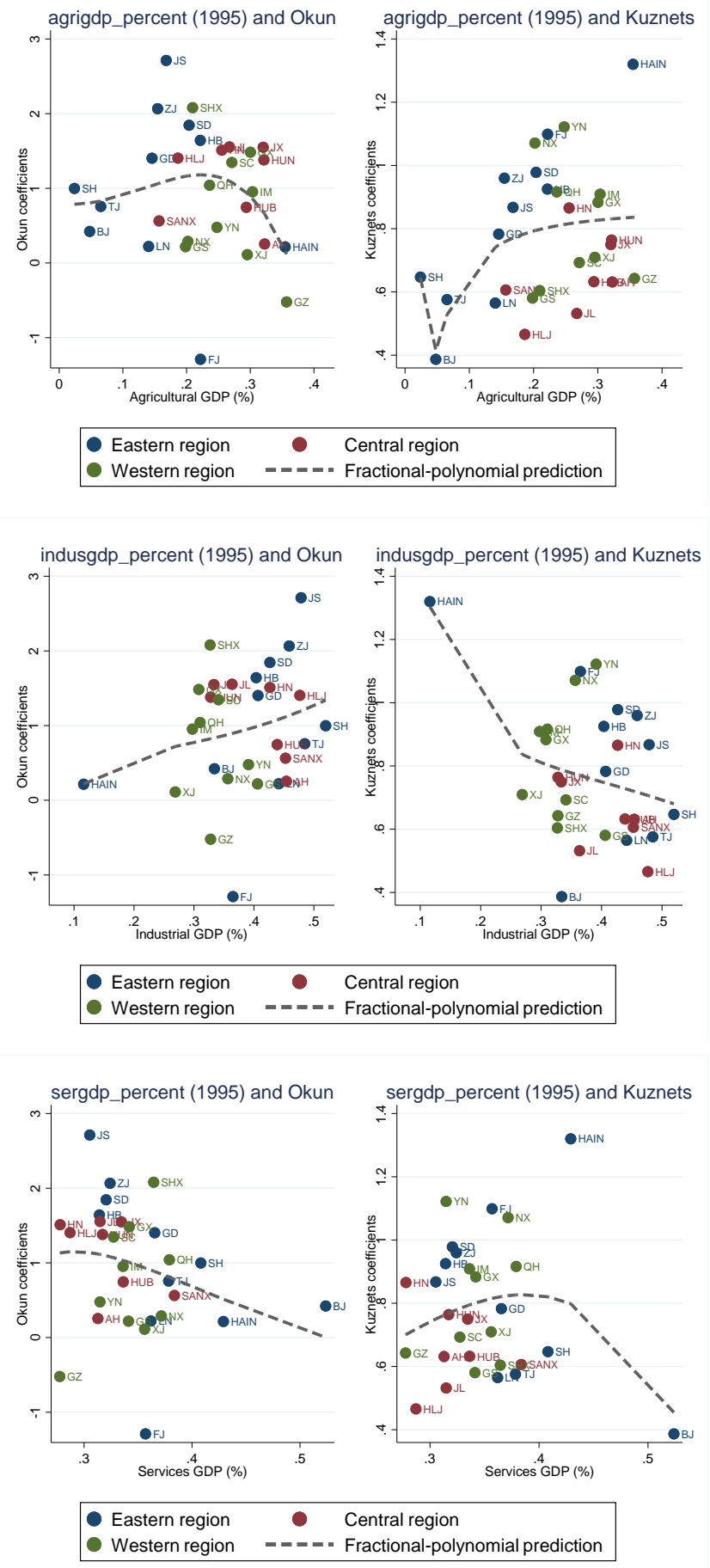


\section{APPENDIX TABLES}

\section{Table B.1. Augmented Dickey-Fuller Test for Unit Root}

\begin{tabular}{lccccc}
\hline & $(1)$ & $(2)$ & $(3)$ & $(4)$ & $(5)$ \\
\multicolumn{1}{c}{ COUNTRY } & $Z(t)$ & $\hat{\varepsilon}_{t-1}^{\tau}$ & $\Delta \hat{\varepsilon}_{t-1}^{\tau}$ & $\Delta \hat{\varepsilon}_{t-2}^{\tau}$ & $\Delta \hat{\varepsilon}_{t-3}^{\tau}$ \\
\hline HP filter, Production-based GHG, 1990-2012 & $-4.926^{* * *}$ & $-0.009^{* * *}$ & $2.761^{* * *}$ & $-2.816^{* * *}$ & $1.065^{* * *}$ \\
Hamilton filter, Production-based GHG, 1990-2012 & $-2.735^{* *}$ & $-0.907^{* * *}$ & 0.401 & 0.281 & 0.447 \\
BK filter, Production-based GHG, 1990-2012 & $-4.767^{* * *}$ & $-0.640^{* * *}$ & 0.226 & $0.623^{* *}$ & $0.697^{* *}$ \\
CF filter, Production-based GHG, 1990-2012 & -0.855 & -0.182 & -0.149 & 0.149 & 0.195 \\
\hline
\end{tabular}

Note: $* * * \mathrm{p}<0.01, * * \mathrm{p}<0.05, * \mathrm{p}<0.1$.

Table B.2. Okun and Kuznets Correlations at the Provincial Level

\begin{tabular}{lcc}
\hline \multicolumn{1}{c}{ VAR. } & $(1)$ & $(2)$ \\
& Okun & Kuznets \\
\hline Growth version & 0.910 & 0.004 \\
Hamilton filtering & 0.399 & 0.745 \\
BK filtering & 0.610 & 0.967 \\
CF filtering & 0.153 & 0.997 \\
Boom & 0.919 & - \\
Bust & 0.950 & - \\
\hline
\end{tabular}

Note: Columns (1) and (2) refer to the baseline calibration, with the HP filter. 


\section{References}

Auffhammer, M., and T. C. Carson, 2008, "Forecasting the path of China's CO2 emissions using province-level information," Journal of Environmental Economics and Management, 55(3), 229247.

Bao, S., Chang, G.H., Sachs, J.D., and W.T. Woo, 2002, "Geographic factors and China's regional development under market reforms 1978-1998," China Economic Review, 13, 89-111.

Baxter, M. and R. G. King, 1999, "Measuring business cycles: Approximate band-pass filters for economic time series," Review of Economics and Statistics, 81, 575-593.

Chang, C., Chen, K., Waggoner, D., and T. Zha, 2015, "Trends and Cycles in China's Macroeconomy," NBER Working Paper No. 21244.

Christiano, L. J. and T. J. Fitzgerald, 2003, "The band pass filter," International Economic Review, $44,435-465$.

Cogley, T., and J. M. Nason, 1995, "Effects of the Hodrick-Prescott Filter on Trend and Difference Stationary Time Series: Implications for Business Cycle Research," Journal of Economic Dynamics and Control, 19, 253-278.

Cohen, G., Jalles, J., Loungani, P., and R. Marto, 2017, "Emissions and Growth: Trends and Cycles in a Globalized World," IMF Working paper, forthcoming.

Csereklyei, Z. and D. Stern, 2015, "Global energy use: Decoupling or convergence?," Energy Economics, 51, 633-641.

Dean, J., Lovely, M., and H. Wuang, 2009, “Are foreign investors attracted to weak environmental regulations? Evaluating the evidence from China," Journal of Development Economics, 90(1), 1-13.

Du, L., Wei, C., and S. Cai, 2012, "Economic development and carbon dioxide emissions in China: Provincial panel data analysis," China Economic Review, 23, 371-384.

Ederington, J., Levinson, A., and J. Minier, 2005, "Footlose and Pollution-Free," Review of Economics and Statistics, 87(1), 92-99.

Grossman, G.M. and A.B. Krueger, 1991, "Environmental impacts of a North American Free Trade Agreement," NBER Working Paper No. 3914.

Grossman, G.M. and A.B. Krueger, 1995, "Economic growth and the environment," Quarterly Journal of Economics, 110, 353-377.

Hamilton, J., 2017, "Why You Should Never Use the Hodrick-Prescott Filter," working paper.

Harvey, A. C., and A. Jaeger, 1993, "Detrending, Stylized Facts and the Business Cycle,” Journal of Applied Econometrics, 8, 231-247. 
He, J., 2006, "Pollution haven hypothesis and environmental impacts of foreign direct investment: The case of industrial emission of sulfur dioxide (SO2) in Chinese provinces," Ecological Economics, 60(1), 228-245.

Hodrick, R.J. and E.C. Prescott, 1981, "Postwar U.S. Business Cycles: An Empirical Investigation," working paper, Northwestern University.

Hodrick, R.J., and E.C. Prescott, 1997, "Postwar U.S. Business Cycles: An Empirical Investigation," Journal of Money, Credit and Banking, 29(1), 1-16.

Intergovernmental Panel on Climate Change (IPCC), 2006, IPCC guidelines for national greenhouse gas inventories.

Jakob, M., Haller, M., and R. Marschinski, 2012, "Will history repeat itself? Economic convergence and convergence in energy use patterns," Energy Economics, 34, 95-104.

Kearsley, A. and M. Riddel, 2010, "A further inquiry into the Pollution Haven Hypothesis and the Environmental Kuznets Curve," Ecological Economics, 69(4), 905-919.

Lenzen, M., Kanemoto, K., Moran, D., and A. Geschke, 2012, "Mapping the Structure of the World Economy," Environmental Science Technology, 46(15), 8374-8381.

Lenzen, M., Moran, D., Kanemoto, K., and A. Geschke, 2013, "Building Eora: A Global Multiregional Input-Output Database at High Country and Sector Resolution," Economic Systems Research, 25(1), 20-49.

Mi, Z., Zhang, Y., Guan, D., Shan, Y., Liu, Z., Cong, R., Yuan, X., and Y. Wei, 2016, "Consumption-based emission accounting for Chinese cities," Applied Energy, 184, 10731081.

Narayan, P.K., 2004, "Are output fluctuations transitory? New evidence from twenty four Chinese provinces," Pacific Economic Review, 9(4), 327-336.

Narayan, P.K., Nielsen, I., and R. Smyth, 2008, "Panel data, cointegration, causality and Wagner's law: empirical evidence from Chinese provinces," China Economic Review, 19(2), 297307

Okun, A., 1962, "Potential GNP: Its Measurement and Significance," Proceedings of the Business and Economics Statistics Section, American Statistical Association, 89-104.

Pao, H. and C. Tsai, 2010, "CO2 emissions, energy consumption and economic growth in BRIC countries," Energy Policy, 38(12), 7850-7860.

Ravn, M. and H. Uhlig, 2002, "On Adjusting the Hodrick-Prescott Filter for the Frequency of Observations," Review of Economics and Statistics, 84 (2), 371-380.

Sheldon, T., 2017, "Asymmetric effects of the business cycle on carbon dioxide emissions," Energy Economics, 61, 289-297. 
Wang, Y., Zhang, P., Huang, D. and C. Cai, 2014, "Convergence behavior of carbon dioxide emissions in China," Economic Modeling, 43, 75-80.

$\mathrm{Xu}$, B. and B. Lin, 2015, "How industrialization and urbanization process impacts on CO2 emissions in China: Evidence from nonparametric additive regression models," Energy Economics, 48, 188-202.

Yang, D.T., 2002, "What has caused regional inequality in China?," China Economic Review, 13, 331-334.

Zhang, L., Yu, J., Sovacool, B. and J. Ren, 2017, "Measuring energy security performance within China: Toward an inter-provincial prospective," Energy, 125, 825-836. 